\title{
APRESENTAÇÃO: SOBRE AMAZÔNIA, RESISTÊNCIA E ESPERANÇA!
}

\section{PRESENTATION: ABOUT THE AMAZON, RESISTANCE AND HOPE!}

Rejane Cleide Medeiros de Almeida ${ }^{1}$

Idelma Santigo da Silva ${ }^{2}$

Vanda Pantoja ${ }^{3}$

A maioria dos artigos que compõe o dossiê Lutas e resistências de comunidades tradicionais e camponesas: produção de saberes e territorialidades está, geograficamente, localizada na parte Oriental da Amazônia Brasileira. Essa porção do Brasil, composta pelos estados do Pará, Maranhão, Amapá, Tocantins e Mato Grosso, abriga diferentes grupos e modos de organização social, e diversas formas de produção de saberes e tecnologias. Nesse amplo território chamado Amazônia Oriental, habitam populações que partilham problemas, soluções e estratégias de sobrevivência frente às demandas da vida cotidiana. As mulheres que habitam esses territórios, e com as quais as autoras e os autores desse dossiê dialogam, são camponesas e indígenas, todas inseridas em coletivos - institucionais ou não - e trabalhando em agendas coletivas. A localização geográfica e social dessas sujeitas as coloca como representantes de uma das principais agendas de luta de segmentos camponeses e indígenas na Amazônia e para além dela: a luta em defesa do território. Claudia Korol (2016, p. 9) afirma que "El acceso

\footnotetext{
${ }^{1}$ Doutora em Sociologia pela Universidade Federal de Goiás (UFG). Docente do curso de Educação do Campo: artes e música do campus Tocantinópolis (UFNT). Atualmente exerce a função de vicecoordenadora- do Programa de Estudos, Cultura e território (PGGCULT)- Universidade Federal do Tocantins (UFT), Campus de Araguaína. Educadora/pesquisadora do Programa Nacional de Educação da Reforma Agrária (PRONERA)- Serviço Social-(UFT). rejmedeiros@uft.edu.br

${ }^{2}$ Doutora em História pela UFG (2010). Professora Adjunta na Universidade Federal Sul e Sudeste do Pará. Atua como docente na Faculdade de Educação do Campo, no Programa de Pós-Graduação em Dinâmicas Territoriais e Sociedade na Amazônia e no Programa de Pós-Graduação em História. É líder do Grupo de Pesquisa Culturas, Identidades e Dinâmicas Sociais na Amazônia Oriental Brasileira (UNIFESSPA/ CNPq). idelmasantiago@gmail.com

${ }^{3}$ Doutora em Ciências Sociais pela Universidade Federal do Pará (UFPA). Docente do Programa de Pósgraduação em Sociologia da Universidade Federal do Maranhão (UFMA) e do curso de licenciatura em Ciências Humanas da UFMA. vanpantoja@gmail.com
} 
a la tierra es uno de los problemas más graves que enfrentan las mujeres rurales en América Latina y en el mundo, y está en la base de muchos otros problemas 'invisibles' para la sociedade". Os muitos outros problemas invisíveis para a sociedade, mencionados pela autora, aparecem nesse dossiê como problematizações propostas pelas autoras e pelos autores nos artigos. Nessas pesquisas, as mulheres aparecem como sujeitas centrais, à frente dos enfrentamentos forjados pelo grupo social na busca de soluções para as questões privadas e públicas. Portanto, esse dossiê faz coro à afirmação de várias autoras que têm realizado pesquisas sobre a importância das mulheres amazônicas nos movimentos sociais, em suas diferentes agendas, e as têm afirmado como sujeitas na linha de frente dos movimentos de resistência.

Em relação às metodologias, ressalta-se que, em cinco dos trabalhos publicados no dossiê, a história oral está presente. Esse não é um dado aleatório. Nesses trabalhos, estão evidenciadas as relações e práticas de conhecimento que contribuem para desmistificar a prática científica como uma prática social não desvinculada de projetos de sociedade, especialmente quando a história oral participa dos processos de afirmação e/ou reconstrução de subjetividades coletivas; memórias contra hegemônicas, recorrentemente silenciadas ou eclipsadas para o conjunto da sociedade. Os processos de investigação científica descritos sinalizam para a instituição de espaços "[...] onde queiramos nos encontrar não mais em função de algum conhecimento que precisa ser preservado ou avançado, mas em função de projetos de vida e de sociedade que julgamos importantes" (STRECK, 2001, p. 264).

Além do trabalho com a história oral, as relações de pesquisa, não raro, incluem a etnografia em vivência e observação de campo, além de algum grau de envolvimento e engajamento dos(as) autores(as) para além dos métodos prescritivos da ciência. No dossiê, Leandra Silvério ressalta, em seu artigo, que produz conhecimento com história oral desde a graduação, passando pelo mestrado e doutorado. Nessa trajetória, ela entrevistou mulheres e homens do Movimento dos Trabalhadores Rurais Sem Terra (MST) - no qual já foi militante orgânica — além de manter relações de fortalecimento da produção agroecológica de assentamentos da reforma agrária. Regilma Santos e Vanda Pantoja desenvolvem pesquisas utilizando a história oral e a etnografia com mulheres do Movimento Interestadual das Quebradeiras de Coco Babaçu (MIQCB) na região de Imperatriz/MA. A primeira tem inserção, como colaboradora do Movimento, desde 2017, 
o que possibilitou sua participação em encontros, reuniões, feiras e outras atividades que viabilizaram o contato com o cotidiano das mulheres. Valéria Santos e Sariza Venâncio - a primeira, agente da Comissão Pastoral da Terra (CPT) em Araguaína/TO, e, a segunda, professora na Universidade Federal do Norte do Tocantins (UFNT) - nos apresentam um trabalho que resulta de encontros, oficinas e outras atividades de campo, que tornaram possível a constituição da Rede de Proteção Mulheres Flores de Sucupira, da qual participaram em diferentes graus de envolvimento. Álvaro Di Matteo, em seu artigo, destaca sua participação em um projeto de investigação de caráter coletivo, no âmbito do Programa Movimientos Populares, Educación y Producción de Conocimiento (Universidad Nacional de Luján, Argentina), em que as organizações e os movimentos campesinos se acordam com os objetivos de investigação, visando a resultados que sejam úteis às iniciativas e aos projetos dessas coletividades. Em seu trabalho, o autor mobiliza material empírico a partir de entrevistas e observação participante. Por fim, Bárbara Ribeiro utilizou-se dessas mesmas técnicas para sua investigação com mulheres indígenas Assuriní da Aldeia Trocará, no Pará. Ela ressalta que esse processo se constituiu uma experiência de aprendizado e, portanto, formadora para as envolvidas.

Essa breve descrição, a autora nos sinaliza percursos, práticas e relações de pesquisa com história oral que podem se aproximar ou mesmo indicar o potencial para os “encontros epistêmicos”, como definido por Ramos Júnior (2019, p. 360): “[...] situações de interação entre diferentes regimes e sujeitos do saber no contexto dos trabalhos de campo em História oral e etnografia." Em primeiro lugar, parecem ser pesquisas preocupadas com os impactos edificantes do conhecimento produzido (SANTOS, 2010). Em segundo, reconhecem os vínculos das narrativas orais com quadros sociais concretos, não para desqualificar, mas para afirmar sujeitos de conhecimentos "outros" nas suas estratégias de comunicar experiência, crítica social e horizonte de expectativas, bem como articular, por suas palavras, o reposicionamento de suas memórias e identidades, comumente em contextos de lutas e conflitos sociais. Em terceiro lugar, para além do objetivo de escutar e fazer "ouvir as vozes subalternas", esses trabalhos talvez nos apontem que, ao lado dos critérios prescritivos dos métodos científicos, estão critérios epistemológicos e pedagógicos advindos e aprendidos nas relações com as coletividades sociais e suas lutas. Por isso, nos alegra sobremaneira que os trabalhos presentes nesse dossiê não se mostrem na perspectiva das metodologias extrativistas (SANTOS, 2018), 
mas no horizonte do reconhecimento de outras práticas de saberes em que as relações de pesquisa movimentam e fazem dialogar, confrontar e retroalimentar (inter) conhecimentos.

Necessariamente, essa discussão nos leva ao pensamento de Freire (1987), para quem, na perspectiva da teoria dialógica da ação, homens e mulheres se encontram para transformar o mundo em colaboração. A teoria, embasada pela ação, desemboca em práxis, e esse é o conhecimento que as autoras e os autores - que elaboraram seus escritos a partir de uma realidade social - trouxeram como reflexões para compor o referido dossiê. Dessa feita, o processo de escrita a partir das diferentes práxis que envolvem realidades de comunidades diversas e distintas formas de operar as resistências, em diferentes territórios, aponta para o que Catarine Walsh (2013) designa como as estruturas históricas das epistemologias subalternas. Assim, as realidades são tomadas a partir da proposta de pensar as insurgências e rebeldias como formas de pedagogias decoloniais desde o subalternizado, que faz sua luta, historicamente, por se afirmar como humano em contraposição à negação que se faz sobre ele. Nesse sentido, resistir praticando os conhecimentos herdados nas comunidades tradicionais como pedagogias decoloniais e de desobediências epistemológicas é o que Catherine Walsh (2013) nos apresenta a partir de suas contribuições sobre pedagogias decoloniais. A pedagogia e o pedagógico não estão pensados enquanto instrumentalização do ensino e transmissão do saber, nem mesmo no campo da educação escolar, mas, sim, como metodologia para as lutas sociais e políticas, ontológicas e epistêmicas para a liberdade: "Las luchas sociales también son escenarios pedagógicos donde los participantes ejercen sus pedagogías de aprendizaje, desaprendizaje, reaprendizaje, reflexión y acción.” (WALSH, 2013, p. 29). A mesma autora contribui com o debate sobre as práticas políticas, epistêmicas, vivenciais e existenciais como sendo marcas nas lutas que podem transformar os padrões de poder e os princípios sobre os conhecimentos. Para ela, as pedagogias são práticas, estratégias e metodologias que se constroem nas resistências para a "[...] afirmación, la (re)existencia y la rehumanización.” (WALSH, 2013, p. 29).

Esperamos que a leitura dos oito artigos deste dossiê instiguem essas e outras questões, ao mesmo tempo em que possam refletir as esperanças contidas nos atos de resistências cotidianas. 
No trabalho "A luta é grande, mermã": as quebradeiras de coco babaçu de Imperatriz entre o machado e o som do macete, Regilma Santos e Vanda Pantoja abordam as formas de existências e resistências cotidianas e coletivas de mulheres quebradeiras de coco babaçu, ligadas ao MIQCB de Imperatriz, Estado do Maranhão. No fazer coletivizado e estratégico dessas mulheres, ainda se inclui a participação e articulação em redes como a Teia dos Povos e a Rede de Agroecologia do Maranhão. A abordagem está ancorada no conceito de resistência cotidiana de James Scott e na perspectiva decolonial, especialmente nas categorias dos Feminismos Plurais.

Valéria Santos, Antònia Laudeci Oliveira Macedo, Lorrany Lourenço Neves e Sariza Venâncio, no artigo Rede de proteção às mulheres camponesas Flores de Sucupira: da luta territorial à luta por autonomia feminina, apresentam a experiência de criação da Rede de Proteção às Mulheres Camponesas Flores de Sucupira. Destacam o trabalho realizado pela CPT Araguaia/TO nesse processo e realizam uma abordagem enfocando dois pontos: a luta das mulheres em defesa de seus territórios e a luta por autonomia político-econômica-sexual. Os aportes teóricos se apoiam, especialmente, no Ecofeminismo de Vandana Shiva e Maria Mies e nas análises do capitalismo patriarcal de Silvia Federici.

Em Pra cá tem campo e pra cá também tem campo, aí nós fica aqui no meio: o campesinato frente à expansão da soja na microrregião de chapadinha (MA), Juscinaldo Almeida realiza uma discussão sobre os processos de luta pela posse e permanência na terra realizada pelo campesinato da microrregião de Chapadinha, no Maranhão. Destaca os processos de mobilização em curso - principalmente os relacionados à criação de assentamentos de reforma agrária - e o acionamento de identidades étnicas, visando, sobretudo, à manutenção da condição camponesa, apesar da forte pressão exercida pelo agronegócio sobre seus territórios. Por isso, o trabalho apresenta uma discussão sobre o Estado e as políticas públicas para a expansão do agronegócio da soja no Maranhão. Essa pesquisa consiste na continuidade de outras já realizadas pelo autor, e é realizada a partir do levantamento bibliográfico e da consulta de dados em fontes secundárias (Instituto Brasileiro de Geografia e Estatística [IBGE] e Instituto Nacional de Colonização e Reforma Agrária [Incra]), utilizando amplo referencial teórico e bibliográfico sobre o tema na literatura brasileira. 
Álvaro Di Matteo, no trabalho Desafios de conhecimento em movimentos populares rurais da Argentina, apresenta uma ampla discussão sobre o processo de "recampesinização" em curso na Argentina. Destaca dois aspectos desse processo: de um lado, o movimento de construção e afirmação da memória e da identidade coletiva, incluindo a ativação de identidades étnicas e saberes tradicionais; de outro, os ensaios com as atividades econômicas campesinas que visam a melhorar as condições de vida e trabalho, articulados ao projeto político da transformação social mais ampla das formas de trabalho, vida rural e comunitária frente ao modelo hegemônico. Ademais, essa discussão é atravessada pela perspectiva de que as referidas questões se constituem, para as organizações campesinas, também como desafios de conhecimento. Isso põe em relevo as articulações das atividades de formação e investigação com vistas a fortalecer suas práticas. Por isso, conforme destaca o autor, o trabalho insere-se em um programa de investigação de caráter coletivo, envolvendo universidade e movimentos populares, e incluindo seus aportes empíricos. Dentre as referências teóricas, encontram-se Walter Benjamin, Raymond Williams e Carlos Walter Porto-Gonçalves.

O texto de Izabelly Carneiro Miranda, Rita Denize de Oliveira e José Augusto Lopes da Silva, Uso e ocupação do solo: o caso da comunidade quilombola Conceição do Mirindeua, Moju/PA problematiza os processos de mudança nos modos de produção de comunidades de cultura tradicional quando em contato com formas externas de produzir. A autora discute as mudanças ocorridas, nessa comunidade, na forma de cultivar a mandioca: de uma forma nativa para um modelo com base nos Sistemas Agroflorestais (SAFs), que introduz formas novas de produção da mandioca e novos sujeitos no campo da produção. A autora problematiza essas questões à luz das mudanças que são experienciadas por comunidades que têm seus territórios ocupados por grandes empreendimentos econômicos.

Compreender a agência de mulheres no contexto das aldeias indígenas é o propósito de Bárbara Ribeiro e Benedita de Moraes Pinto em Saberes, poderes e atuação de mulheres na aldeia indígena Assuriní do Trocará, Município de Tucuruí/PA. A autora enfatiza a participação da mulher Assuriní nos processos que envolvem a comunidade como um todo, desde a organização de rituais que enfatizam a agência da mulher indígena em aspectos internos ao grupo, até a organização dessa sujeita em agendas que dizem respeito às questões da educação e da defesa do território. A autora conclui que a 
participação da mulher Assuriní, nos processos da vida social do grupo, se dá tanto na esfera privada como na pública.

Os escritos de Mariana Cunha Pereira e Cláudia Araújo Moreira - Mulher rural: identidades e conflitos de gênero nos processos produtivos - apresentam reflexões sobre as experiências vivenciadas pelas mulheres trabalhadoras rurais no projeto, a geração de trabalho e renda em processos de desenvolvimento agroecológico. As elaborações das autoras apresentam discussões que vão desde os processos produtivos até a legislação e o planejamento de políticas públicas para o campo, no Brasil, e as representações que as mulheres criam de si. Como destaque para o resultado da escrita sobre a experiência, as autoras chamam a atenção para o fato de que o trabalho produtivo no campo tem base nas relações de saber/poder entre os gêneros, e que desenvolver projetos educativos pode contribuir com processos construtivos de reelaboração de identidades de gênero.

Com o título do artigo Mulheres em luta pela reforma agrária popular: relações de gênero, desfazendo opressões, machismo e sexismo, Leandra Domingues Silvério propõe reflexões sobre as mulheres em luta pela reforma agrária popular organizada pelo MST. O objetivo é dialogar sobre as experiências sociais na/da luta pela terra, interpretando significados das práxis emancipadoras desenvolvidas pelas mulheres que modificaram suas perspectivas nas/das relações de gênero, movendo e desfazendo estruturas patriarcais capitalistas de opressão, machismo e sexismo. Como resultado da pesquisa, a autora identifica que, em tempos da pandemia da Covid-19, as milhares de famílias do MST pelo País têm sido, pedagogicamente, exemplo de solidariedade ao realizarem doações de toneladas de alimentos saudáveis para quem está em situação de vulnerabilidade econômica e social.

\section{Referências}

FREIRE, Paulo. Pedagogia do Oprimido. 17ª ed. Rio de Janeiro, Paz e Terra, 1987.

KOROL, Claudia. Somos tierra, semilla, rebeldía. Mujeres, tierra y territorio en América Latina. Argentina: coedición de GRAIN, Acción por la Biodiversidad y América Libre, 2016.

RAMOS JÚNIOR, Dernival Venâncio. Encontros epistêmicos e a formação do pesquisador em História Oral. História Oral, v. 22, n. 1, p. 359-372, 2019. 
SANTOS, Boaventura de Sousa. O fim do império cognitivo: a afirmação das epistemologias do Sul. Coimbra: Almedina, 2018.

SANTOS, Boaventura de Sousa. Para além do pensamento abissal: das linhas globais a uma ecologia de saberes. In: SANTOS, Boaventura de Sousa; MENESES, Maria Paula (Orgs.). Epistemologias do Sul. São Paulo: Cortez, 2010, p. 31-67.

STRECK, Danilo. Pesquisar é pronunciar o mundo: notas sobre método e metodologia. In: BRANDÃO, Carlos Rodrigues; STRECK, Danilo (Orgs.). Pesquisa participante: a partilha do saber. Aparecida/SP: Ideias \& Letras, 2006, p. 259-276.

WALSH, C. Pedagogías decoloniales. Prácticas insurgentes de (re) existir, (re) vivir. Quito: Ed. Abya Yala, 2013. Tomo I y Tomo II. 